\title{
Vaping and Adolescents' Characteristics: Implications for Prevention and Intervention
}

\author{
Ava Chae ${ }^{1}$, Janet Hanson ${ }^{1}$ \\ ${ }^{1}$ Manhattan High School, Manhattan, KS, USA \\ DOI: https://doi.org/10.47611/jsrhs.v10i2.1421
}

\begin{abstract}
Vaping in the United States has increased in the past decade especially among teens and young adults, causing a rise in public concern for their health. What is relatively scarce in the previous research and the current discussion is the question about what groups of adolescents may be more vulnerable to vaping. This research investigates this very issue by analyzing the associations between vaping use and adolescents' individual characteristics using a national survey of drug use among U.S. adolescents ("Monitoring the Future: A Continuing Study of American Youth (12thGrade Survey)", 2018). The findings for logistic regression show that students who struggle with academics and skip school are more vulnerable to vaping than other students. In addition, there is a greater chance of vaping with those students going out more often than others. The amount of money students earn from a job and other work may also be increasing the chance for vaping. The findings can be valuable elements in designing a program of effective prevention and intervention of vaping in the U.S.
\end{abstract}

\section{Introduction}

Vaping in the United States has increased in the past decade especially among teens and young adults, causing an increase in public concern for their health. Numerous reports specify (or indicate) that vaping is highly prevalent among U.S. adolescents. A long-term national survey of substance use among U.S. adolescents reveals that vaping was most used by the group among tobacco-like products in 2017 and that there has been a sharp increase of $10 \%$ in vaping among 12th graders between 2017 and 2018 (Miech et al., 2019). According to the same survey, 25\% of 12th graders have used vaped nicotine or flavoring in the past 30 days. This prevalence of vaping among adolescents is surprising considering that vaping was first introduced to the American market in 2007 (Raven, 2019).

When introduced, vapes, or e-cigarettes, were marketed as a tool for adults to quit smoking cigarettes and was advocated by e-cigarette manufacturing companies and some health experts (Zernike, 2018). However, the abrupt increase in vaping among adolescents has caused health-related concerns and a call to action by parents, school officials, and health experts (Kong \& Krishnan-Sarin, 2017). Several recent studies have linked adolescent vaping, smoking, and other substance use. There are also reports of injuries and serious health-related consequences from longterm use of vaping products (Lu et al., 2020). For example, a recent New York Times' article ("I can't stop": schools struggle with vaping explosion") discusses the addictive power of vaping among young people in the country (Zernike, 2018).

The question "what groups of teenagers are more likely to experience vaping" is important to parents, health professionals, and policymakers. This research attempts to answer that question using a series of statistical analysis techniques, including logistic regression, on a long-term, national survey of drug use by 12 th-grade students in the U.S. 
While public interest and academic research on the topic of vaping and adolescent health are growing, published academic work and news articles are more about reporting trends in the use of vaping products, the associations between vaping, smoking and other types of substances, and susceptibility to e-cigarette use (Kwon et al., 2019).

These studies and reports have increased awareness of vaping issues and potential health-related consequences among adolescents and within communities. This, in turn, has led to discussion about the need for action in terms of prevention and intervention through different means such as education and regulation (Prochaska, 2019). What is relatively scarce in the previous research and the current discussion about adolescent vaping, is the question as to what groups of adolescents may be more susceptible to vaping. This research aims to investigate this very issue by analyzing the associations between vaping and individual adolescents' characteristics.

This study develops three hypotheses linking certain individual characteristics with vaping adoption, drawing upon previous studies. The findings of logistic regression analysis show that the individual characteristics of students (school performance, economic status, and social activity) are associated with vaping use. The study develops discussion and implications of the findings and provides conclusions regarding prevention and intervention of adolescent vaping use.

\section{Literature Review \& Hypothesis Development}

Vaping is a relatively new phenomenon (Raven, 2019). The literature is less clear on what theory (or theoretical framework) may be helpful to predict vaping among adolescents. For this reason, developing hypotheses in this research relies on the findings of previous studies.

Specifically, there are only a handful of studies on vaping among adolescents and individual characteristics of these adolescents. These studies can be divided into two categories. The first category includes studies examining susceptibility to vaping (Kaleta et al., 2019; Kwon et al., 2018),

For example, one study reported the findings from a survey of 1,693 students attending schools in a district in central Poland (Kaleta et al., 2019). The study examined adolescents' individual characteristics (e.g., money available per month) and family-related factors (e.g., parents' educational levels, parental smoking, parental e-cigarette use), which make adolescents more susceptible to vaping. Similarly, a U.S.-based study attempted to identify such factors drawing a sample (N=9853) from the Population Assessment of Tobacco and Health (PATH) Study Wave 1. Two questions were used to measure susceptibility: "Do you think that you will try an e-cigarette soon?" and "If one of your best friends were to offer you an e-cigarette, would you use it?" (Kwon et al., 2018). Kwon et al.' study suggests that students' individual factors such as psychology and personality are associated with increased susceptibility. Questions remain as to how much susceptibility is associated with actual behavior.

The second category of research includes a limited number of studies examining actual vaping among adolescents and the factors associated with vaping. One study (Kristjansson et al., 2018) compared non-smokers, e-cigarette (EC) users, and dual users (doing both smoking and vaping). The authors reported some significant differences between non-smokers and EC users in terms of social profiles. Overall, EC users have less "social support and parental monitoring" and lower academic performance than those who have never smoked. Also, they tend to spend more time outside of their homes at night than non-smokers. The author's study was conducted with a sample of middle school and high school students living in West Virginia. Another study (Park, Lee, \& Min, 2017) looked at factors associated with e-cigarette use in South Korea. The findings show significant associations between the students' demographics (e.g., income and/or allowance) and vaping. A literature review-based study (Perikleous et al., 2018) suggests that adolescents with certain characteristics may be more vulnerable to vaping than others. Such characteristics include school performance (e.g., lower academic performance), economic status (e.g., being in employment), and social activity (e.g., for a party).

Largely drawn upon the second group of research studies, the following hypotheses were developed: 
Hypothesis 1: School performance is highly associated with vaping. Those adolescents lower in academic performance, are more likely to experience vaping.

Hypothesis 2: Economic status is highly associated with vaping. Those with more access to money (e.g., through employment), are more likely to experience vaping.

Hypothesis 3: Social activity (e.g., a party) is highly associated with vaping use. Those with more active social lives are more likely to experience vaping.

\section{Research Methodology}

\section{Data}

It is possible that vaping among adolescents can vary between countries (e.g., U.S. vs Poland) and between regions within the same country. The research questions need a national-level survey of vaping use among adolescents in the U.S. Also, to test the aforementioned hypotheses, the survey has to include such questions as to whether an adolescent has ever vaped and his or her personal characteristics (e.g., academic performance, economic status). Also, to increase the generalizability of the study's expected findings, a national survey with a large sample size was desired.

This research relies on survey data of drug use by U.S. adolescents ("Monitoring the Future: A Continuing Study of American Youth (12th-Grade Survey)", 2018). The survey is a long-term national survey conducted annually by the Inter-University Consortium for Political and Social Research at the University of Michigan (Miech et al., 2018). The survey covers an extensive list of questions about substance use, including vaping, and 12th-grade U.S. students' demographics, including employment, income, recreation, and aspirations. Thus, the survey data is suitable for this research, as it satisfies the previously mentioned conditions for testing the research hypotheses.

Specifically, there are 14,502 students in the 2018 survey data. The data contains missing values for the column (y variable) asking "whether student has ever vaped before" for 10,179 students. This resulted in 4,323 valid samples, which include 2,405 never vaped users (NU) and 1,918 ever vaped users (VU). This shows 44\% of 12th graders have vaped. $45 \%$ of male and $43 \%$ of female students reported they have vaped.

\section{Variables}

The survey data contained 184 variables about student demographics and other personal characteristics. All the variables were reviewed considering the hypotheses and variable selection was conducted with respect to students' characteristics. The results are ten independent variables with detailed descriptions in Table 1. These variables include school performance (e.g., V2179), economic status (e.g., V2191), and social activity (e.g., V2194).

Next, the quality of the data with ten independent variables and the dependent variable was checked. 862 students that have one or more missing values in at least one of the independent variables were removed from further analysis. This resulted in a sample of 3,461 students for statistical analysis. Among the sample, 1,553 students responded "Yes" to the questions "Have you every vaped?", representing a 44.8 percent of the sample.

\section{Table 1}

\section{A Description of Variables}

\begin{tabular}{|c|c|c|}
\hline Variables & $\frac{\text { Variable }}{\text { code }}$ & $\underline{\text { Variable description }}$ \\
\hline $\begin{array}{c}\text { School } \\
\text { perfor- } \\
\text { mance }\end{array}$ & V2176 & $\begin{array}{c}\text { During the last four weeks, how many whole days of school have you } \\
\text { missed? }\end{array}$ \\
$\begin{array}{c}\text { 1="None" 2="1 Day" 3="2 Days" 4="3 Days" 5="4-5 Days" 6="6-10 } \\
\text { Days" 7="11 or More" }\end{array}$ \\
\hline
\end{tabular}




\begin{tabular}{|c|c|c|}
\hline & V2178 & $\begin{array}{c}\text { During the last four weeks, how often have you gone to school, but } \\
\text { skipped a class when you weren't supposed to? } \\
1=\text { "Not at all" } 2=\text { " } 1 \text { or } 2 \text { times" } 3=\text { " } 3-5 \text { times" } 4=\text { " } 6-10 \text { times" } 5=" 11-20 \\
\text { times" } 6=\text { "More than } 20 \text { times" }\end{array}$ \\
\hline & V2179 & $\begin{array}{l}\text { Which of the following best describes your average grades so far in } \\
\text { high school? } \\
9=" \mathrm{~A}(93-100) " 8=" \mathrm{~A}-(90-92) " 7=" \mathrm{~B}+(87-89) " 6=" \mathrm{~B}(83-86) " 5=\text { "B- } \\
(80-82) " 4=" \mathrm{C}+(77-79) " 3=" \mathrm{C}(73-76) " 2=" \mathrm{C}-(70-72) " 1=" \mathrm{D} \text { (69 or be- } \\
\text { low)" }\end{array}$ \\
\hline \multirow{3}{*}{$\begin{array}{c}\text { Economic } \\
\text { status }\end{array}$} & V2191 & $\begin{array}{l}\text { On the average over the school year, how many hours per week do you } \\
\text { work in a paid or unpaid job? } \\
\begin{array}{c}1=\text { "None" } 2=" 5 \text { or fewer hours" } 3=\text { " } 6 \text { to } 10 \text { hours" } 4=" 11 \text { to } 15 \text { hours" } \\
5=" 16 \text { to } 20 \text { hours" } 6=" 21 \text { to } 25 \text { hours" } 7=" 26 \text { to } 30 \text { hours" } 8=\text { "More } \\
\text { than } 30 \text { hours" }\end{array}\end{array}$ \\
\hline & V2192 & $\begin{array}{l}\text { During an average week, how much money do you get from a job or } \\
\text { other work? } \\
1=" \text { None" } 2=" \$ 1-5 " 3=" \$ 6-10 " 4=" \$ 11-20 " 5=\$ 21-35 " 6=" \$ 36-50 " \\
7=" \$ 51-75 " 8=" \$ 76-125 " 9=" \$ 126-175 " 10=" 176+"\end{array}$ \\
\hline & V2193 & $\begin{array}{c}\text { During an average week, how much money did you get from other } \\
\text { sources (allowances, etc.)? } \\
1=\text { "None" } 2=" \$ 1-5 \text { " } 3=" \$ 6-10 " 4=" \$ 11-20 " 5=\$ 21-35 " 6=" \$ 36-50 " \\
7=" \$ 51-75 " 8=" \$ 76-125 " 9=" \$ 126-175 " 10=" 176+"\end{array}$ \\
\hline \multirow{3}{*}{$\begin{array}{l}\text { Social ac- } \\
\text { tivity }\end{array}$} & V2194 & $\begin{array}{l}\text { During a typical week, how many evenings do you go out for fun and } \\
\text { recreation? } \\
\begin{array}{c}1=\text { "Less than one" } 2=\text { "One" } 3=\text { "Two" } 4=\text { "Three" } 5=\text { "Four or Five" } \\
6=\text { "Six or Seven" }\end{array}\end{array}$ \\
\hline & V2195 & $\begin{array}{l}\text { On the average, how often do you go out with a date (or your } \\
\text { spouse/partner)? } \\
1=\text { "Never" } 2=\text { "Once a month or less" } 3=\text { " } 2 \text { or } 3 \text { times a month" } \\
4=\text { "Once a week" } 5=\text { " } 2 \text { or } 3 \text { times a week" } 6=\text { "Over } 3 \text { times a week" }\end{array}$ \\
\hline & V2196 & $\begin{array}{l}\text { During an average week, how much do you usually drive a car, truck, or } \\
\text { motorcycle? } \\
\begin{array}{l}1=\text { "Not at all" } 2=" 1 \text { to } 10 \text { miles" } 3=" 11 \text { to } 50 \text { miles" } 4=" 51 \text { to } 100 \\
\text { miles" } 5=" 100 \text { to } 200 \text { miles" } 6=\text { "More than } 200 \text { miles" }\end{array}\end{array}$ \\
\hline $\begin{array}{c}\text { Dependent } \\
\text { variable }\end{array}$ & V2566 & $\begin{array}{l}\text { To "vape" is to use a device such as a vape-pen, an e-cigarette, an e- } \\
\text { hookah, or e-vaporizer to inhale a mist or vapor into the lungs. Have } \\
\text { you ever vaped? } \\
\text { 0="No" } 1=\text { "Yes" }\end{array}$ \\
\hline
\end{tabular}

Note. The variables' definitions are based on the survey codebook (Miech et al., 2018).

\section{Analysis of Data}

Analysis was a two-step process: running a generalized linear model (GLM) and running a special case of GLM called bestglm(). First, the nine independent variables and one dependent variable ("ever vaped?") were used as the input for a GLM where the logit function is the default function for a binomial outcome variable. The goal of the logic is to find out which independent variables are important predictors for the dependent variable ( 0 for NO vaping and 1 for YES vaping). 
Second, the R function called bestglm (McLeod \& Xu, 2010) was also applied as this technique helps "variable or feature selection" by choosing the best subset of independent variables for predicting the outcome variable. While the logit function reveals the significance of individual independent variables in predicting the outcome, the function bestglm discovers a subset of independent variables that can maximize the accuracy of a model in predicting the outcome. This indicates that the results of the bestglm function can complement that of the logit function model.

Results

Table 2

Means, Standard Deviations, and Correlations with Confidence Intervals.

\begin{tabular}{|c|c|c|c|c|c|c|c|c|c|c|c|}
\hline Variable & $M$ & $\begin{array}{l}S \\
D\end{array}$ & 1 & 2 & 3 & 4 & 5 & 6 & 7 & 8 & 9 \\
\hline 1. V2176 & $\begin{array}{c}1 . \\
61\end{array}$ & $\begin{array}{r}1 . \\
21\end{array}$ & & & & & & & & & \\
\hline \multicolumn{12}{|l|}{ Missing school } \\
\hline 2. V2178 & $\begin{array}{r}1 . \\
36 \\
\end{array}$ & $\begin{array}{r}0 . \\
83 \\
\end{array}$ & $.45^{* *}$ & & & & & & & & \\
\hline Skipping class & & & $\begin{array}{r}{[.43,} \\
.48]\end{array}$ & & & & & & & & \\
\hline 3. V2179 & $\begin{array}{r}6 . \\
90 \\
\end{array}$ & $\begin{array}{r}1 . \\
84\end{array}$ & $-.14 * *$ & $-.17 * *$ & & & & & & & \\
\hline Average grades & & & $\begin{array}{r}{[-.17,-} \\
.11]\end{array}$ & $\begin{array}{r}{[-.20,-} \\
.13]\end{array}$ & & & & & & & \\
\hline 4. V2191 & $\begin{array}{r}3 . \\
11\end{array}$ & $\begin{array}{r}2 . \\
31\end{array}$ & $.17 * *$ & $.14 * *$ & $-.08 * *$ & & & & & & \\
\hline Hours of work & & & $\begin{array}{r}{[.13,} \\
.20]\end{array}$ & $\begin{array}{r}{[.10,} \\
.17]\end{array}$ & $\begin{array}{r}{[-.11,-} \\
.05]\end{array}$ & & & & & & \\
\hline 5. V2192 & $\begin{array}{c}4 . \\
70\end{array}$ & $\begin{array}{r}3 . \\
75\end{array}$ & $.16^{* *}$ & $.12 * *$ & $-.05 * *$ & $.77^{* * *}$ & & & & & \\
\hline Income & & & $\begin{array}{r}{[.12,} \\
.19]\end{array}$ & $\begin{array}{r}{[.09,} \\
.15]\end{array}$ & $\begin{array}{r}{[-.08,-} \\
.01]\end{array}$ & $\begin{array}{r}{[.76} \\
.78]\end{array}$ & & & & & \\
\hline 6. V2193 & $\begin{array}{r}2 . \\
81\end{array}$ & $\begin{array}{r}2 . \\
42 \\
\end{array}$ & $.11^{* *}$ & $.10^{* *}$ & $-.04 *$ & $-.06 * *$ & $-.04 *$ & & & & \\
\hline Allowance & & & $\begin{array}{r}{[.08,} \\
.14]\end{array}$ & $\begin{array}{r}{[.07,} \\
.13]\end{array}$ & $\begin{array}{r}{[-.08,-} \\
.01]\end{array}$ & $\begin{array}{r}{[-.10,-} \\
.03]\end{array}$ & $\begin{array}{r}{[-.07,-} \\
.01]\end{array}$ & & & & \\
\hline 7. V2194 & $\begin{array}{r}2 . \\
84 \\
\end{array}$ & $\begin{array}{r}1 . \\
35\end{array}$ & $.12 * *$ & $.08^{* *}$ & -.02 & $.04 *$ & $.10^{* *}$ & $.19^{* *}$ & & & \\
\hline Social activity & & & $\begin{array}{r}{[.08,} \\
.15] \\
\end{array}$ & $\begin{array}{r}{[.05,} \\
.12] \\
\end{array}$ & $\begin{array}{r}-.05 \\
.01] \\
\end{array}$ & $\begin{array}{r}{[.01,} \\
.08]\end{array}$ & $\begin{array}{r}{[.07,} \\
.13]\end{array}$ & $\begin{array}{r}{[.16,} \\
.22]\end{array}$ & & & \\
\hline 8. V2195 & $\begin{array}{r}2 . \\
26 \\
\end{array}$ & $\begin{array}{r}1 . \\
57\end{array}$ & $.08^{* *}$ & $.07 * *$ & .00 & $.16^{* *}$ & $.14 * *$ & $.12 * *$ & $.27 * *$ & & \\
\hline Dating & & & $\begin{array}{r}{[.05,} \\
.11]\end{array}$ & $\begin{array}{r}.03, \\
.10]\end{array}$ & $\begin{array}{r}{[-.03} \\
.04]\end{array}$ & $\begin{array}{r}{[.12,} \\
.19]\end{array}$ & $\begin{array}{r}{[.11,} \\
.18]\end{array}$ & $\begin{array}{c}{[.09,} \\
.15]\end{array}$ & $\begin{array}{r}{[.24,} \\
.30]\end{array}$ & & \\
\hline 9. V2196 & $\begin{array}{c}3 . \\
00 \\
\end{array}$ & $\begin{array}{r}1 . \\
63\end{array}$ & $.12 * *$ & $.11^{* *}$ & $.07 * *$ & $.27 * *$ & $.29 * *$ & $.14 * *$ & $.21^{* *}$ & $.22 * *$ & \\
\hline Driving & & & {$[.09$} & {$[.07$,} & {$[.03$,} & {$[.24$,} & {$[.26$,} & {$[.10$} & {$[.18$,} & {$[.19$,} & \\
\hline
\end{tabular}




\begin{tabular}{|c|c|c|c|c|c|c|c|c|c|c|c|}
\hline & & & $.15]$ & $.14]$ & $.10]$ & $.30]$ & $.32]$ & .17] & $.24]$ & $.25]$ & \\
\hline 10. V2566 & $\begin{array}{r}0 . \\
45 \\
\end{array}$ & $\begin{array}{r}0 . \\
50 \\
\end{array}$ & $.20 * *$ & $.16^{* *}$ & $-.08 * *$ & $.17 * *$ & $.19 * *$ & $.11 * *$ & $.22 * *$ & $.17 * *$ & $.24 * *$ \\
\hline Vaping & & & $\begin{array}{r}{[.17,} \\
.24]\end{array}$ & $\begin{array}{r}{[.13,} \\
.20]\end{array}$ & $\begin{array}{r}{[-.11,-} \\
.05]\end{array}$ & $\begin{array}{r}{[.14,} \\
.21]\end{array}$ & $\begin{array}{r}{[.16,} \\
.22]\end{array}$ & $\begin{array}{r}{[.07,} \\
.14]\end{array}$ & $\begin{array}{r}{[.19} \\
.25]\end{array}$ & $\begin{array}{r}{[.14,} \\
.20]\end{array}$ & $\begin{array}{r}{[.21,} \\
.27]\end{array}$ \\
\hline
\end{tabular}

Note. M and SD are used to represent mean and standard deviation, respectively. Values in square brackets indicate the $95 \%$ confidence interval for each correlation. The confidence interval is a plausible range of population correlations that could have caused the sample correlation (Cumming, 2014). * indicates $\mathrm{p}<.05 . * *$ indicates $\mathrm{p}<.01$.

The descriptive statistics is summarized in Table 2. The results show a strong correlation between vaping use and all nine independent variables. The behavior of missing school more frequently, regardless of the reason, as well as often skipping class without permission is shown to be highly correlated with vaping. In contrast, academic grades have an inverse relationship with the dependent variable. As seen in Table 2, all three variables linked to hypothesis 2 (economic status) are positively correlated with vaping use. Hours of work and the amount of money received from work, allowance, or other sources are positively correlated with vaping use. Students who go out more often for fun, recreation, and dates, along with those who drive more, variables which are linked to hypothesis 3 , have a positive correlation with vaping use as well.

Table 3

Results of Logit Function Model and Bestglm Model.

\begin{tabular}{|c|c|c|c|c|c|c|}
\hline \multirow{3}{*}{ Predictors } & Variables & \multicolumn{3}{|c|}{ Logit Results } & \multicolumn{2}{c|}{ Bestglm() Results } \\
\cline { 2 - 6 } & Coefficient & p-value & $\begin{array}{c}\text { Signifi- } \\
\text { cant? }\end{array}$ & Coefficient & Selected? \\
\hline \multirow{4}{*}{$\begin{array}{c}\text { School per- } \\
\text { formance }\end{array}$} & $\begin{array}{c}\text { V2176 (Missing } \\
\text { school) }\end{array}$ & 0.22087 & $1.10 \mathrm{e}-09^{* * *}$ & Yes & 0.22701624 & Yes \\
\cline { 2 - 6 } & $\begin{array}{c}\text { V2178 (Skipping } \\
\text { class) }\end{array}$ & 0.17134 & $0.001053^{* *}$ & Yes & 0.17928925 & Yes \\
\cline { 2 - 7 } & $\begin{array}{c}\text { V2179 (Average } \\
\text { grades) }\end{array}$ & -0.07013 & $0.000696^{* * *}$ & Yes & -0.07347058 & Yes \\
\hline \multirow{3}{*}{$\begin{array}{c}\text { Economic } \\
\text { status }\end{array}$} & $\begin{array}{c}\text { V2191 (Hours of } \\
\text { work) }\end{array}$ & 0.02930 & 0.240510 & No & & No \\
\cline { 2 - 7 } & V2192 (Income) & 0.04714 & $0.0020193^{* * *}$ & Yes & 0.05764114 & Yes \\
\cline { 2 - 7 } & V2193 (Allowances) & 0.03675 & $0.020193^{*}$ & No & & No \\
\hline \multirow{2}{*}{$\begin{array}{c}\text { Social ac- } \\
\text { tivity }\end{array}$} & V2194 (Going out) & 0.23172 & $2.49 \mathrm{e}-15^{* * *}$ & Yes & 0.23771189 & Yes \\
\cline { 2 - 7 } & V2195 (Dating) & 0.09947 & $4.81 \mathrm{e}-05^{* * *}$ & Yes & 0.10483451 & Yes \\
\cline { 2 - 7 } & V2196 (Driving) & 0.20084 & $2.92 \mathrm{e}-16^{* * *}$ & Yes & 0.20885999 & Yes \\
\hline
\end{tabular}

Note. Significance codes: '***’ 0.001 '**’ 0.01 '*’ 0.05 ‘’ 0.1 ' ’ 1

The results of the logit function model and the bestglm model are summarized in Table 3. First, the hypothesis regarding school performance is supported. The results from the logic model show that all three variables related to school performance are significant predictors of vaping among adolescents. There is a high chance of vaping among the students who describe their average grade as low. Skipping school appears to be highly associated with vaping as well. The bestglm model selected low grade and skipping school as two of the eight best variables in predicting vaping.

The support of Hypothesis \#2 (economic status) is weak. The results of both models show that, out of the three variables, the amount of money the students get from a job or other work is the only variable associated with 
vaping. The other two variables (the number of working hours per week and the amount of money from other sources like allowance) are found not to be not strong predictors of vaping.

Hypothesis \#3 tested the association between social activity t (e.g., a party) and vaping. The results of both models strongly support this relationship. All three variables appear to be predictors of vaping. Going out for fun and recreation and going out on a date are shown to be closely linked to vaping. Likewise, the amount of driving is positively associated with vaping.

\section{Discussion and Conclusions}

Hypothesis 1 (school performance) and 3 (social activity) are strongly supported, while Hypothesis 2 (economic status) is weakly supported. Students with lower academic performance are more likely to vape because school performance is highly associated with vaping use. A student's economic status and access to money is not associated with vaping use. More active social lives are highly associated with vaping use, therefore, students who go out more frequently are more likely to vape.

This research finds that school performance and social culture could be important predictors of vaping among adolescents. Those who struggle with academics and skip school are more vulnerable to involvement in vaping than other students. In addition, there is a greater chance of vaping for those students going out more often than others. These two factors appear to be inseparable since one may reinforce the other. While being considered less significant, the amount of money students earn from a job and other work may be increasing the chance for vaping.

For prevention and intervention, parents, school officials, and health professionals should pay close attention to these student characteristics. For parents, for example, their students may not much rely on allowances to purchase vaping devices. This study suggests that money from a job may provide students with the resources to buy vaping products and parents may be overlooking this. Also, parental role-modeling and supervision may need to be emphasized as this study finds that social culture is closely related to vaping. Low school performance is especially undesirable, as substance use increases among adolescents in the U.S. Parents and school officials should intervene in the behavior of skipping school as early as possible. Health professionals can work with students struggling with vaping through behavioral changes of both students and parents, such as encouraging activities with parental supervision.

The literature has suggested that vaping is linked with the use of other substances and it can lead to physical and behavior problems among adolescents (Kong \& Krishnan-Sarin, 2017). Despite these concerns and potential health issues, vaping among adolescents has been increasing at an alarming rate (Miech et al., 2019). There has been relatively little research on the vulnerability of certain students to vaping. This study, using a long-term, national survey of vaping among U.S. adolescents, has filled the gap in the literature. The findings of this study can be valuable inputs to designing a program of effective prevention and intervention of vaping in the U.S.

\section{Acknowledgment of Assistance}

The author appreciates Ms. Janet Hanson (Gifted Counselor, MHS) sponsoring this research project.

\section{References}

Kaleta, D., Niedzin, M., Jankowska, A., \& Polańska, K. (2019). Predictors of E-cigarette use susceptibility-A study of young people from a socio-economically disadvantaged rural area in Poland. International Journal of Environmental Research and Public Health, 16(20), 3935.

Kong, G., \& Krishnan-Sarin, S. (2017). A call to end the epidemic of adolescent E-cigarette use. Drug and alcohol dependence, 174, 215-221. 
Kristjansson, A. L., Mann, M. J., Smith, M. L., \& Sigfusdottir, I. D. (2018). Social profile of middle school-aged adolescents who use electronic cigarettes: implications for primary prevention. Prevention Science, 19(6), 805-812. Kwon, E., Seo, D.-C., Lin, H.-C., \& Chen, Z. (2018). Predictors of youth e-cigarette use susceptibility in a US nationally representative sample. Addictive behaviors, 82, 79-85.

Lu, M. A., Jabre, N. A., \& Mogayzel Jr, P. J. (2020). Vaping-related lung injury in an adolescent. American journal of respiratory and critical care medicine $(\mathrm{ja})$.

McLeod, A., \& Xu, C. (2010). bestglm: Best subset GLM. https://cran.r-project.org/web/packages/bestglm/bestglm.pdf.

Miech, R., Johnston, L., O’Malley, P. M., Bachman, J. G., \& Patrick, M. E. (2019). Adolescent vaping and nicotine use in 2017-2018-US national estimates. New England Journal of Medicine, 380(2), 192-193.

Miech, R. A., Johnson, L. D., Bachman, J. G., O'Malley, P. M., \& Schulenberg, J. E. (2018). Monitoring the Future: A Continuing Study of American Youth (12th-Grade Survey), 2018. ICPSR (Inter-University Consortium for Political and Social Research).

Park, S., Lee, H., \& Min, S. (2017). Factors associated with electronic cigarette use among current cigarette-smoking adolescents in the Republic of Korea. Addictive behaviors, 69, 22-26.

Pepper, J. K., Coats, E. M., Nonnemaker, J. M., \& Loomis, B. R. (2019). How do adolescents get their e-cigarettes and other electronic vaping devices? American Journal of Health Promotion, 33(3), 420-429.

Perikleous, E. P., Steiropoulos, P., Paraskakis, E., Constantinidis, T. C., \& Nena, E. (2018). E-Cigarette Use Among Adolescents: An Overview of the Literature and Future Perspectives. Frontiers in public health, 6, 86-86.

Prochaska, J. J. (2019). The public health consequences of e-cigarettes: a review by the National Academies of Sciences. A call for more research, a need for regulatory action. Addiction, 114(4), 587-589.

Raven, K. (2019). Teen Vaping Linked to More Health Risks. https://www.yalemedicine.org/stories/teen-vaping/. Zernike, K. (2018). I can't stop": schools struggle with vaping explosion. New York Times, A1. 